\title{
Ig Constant Region Effects on Variable Region Structure and Function
}

\author{
Alena Janda ${ }^{1}$, Anthony Bowen ${ }^{1}$, Neil S. Greenspan ${ }^{2}$ and Arturo Casadevall ${ }^{3 *}$ \\ ${ }^{1}$ Department of Microbiology and Immunology, Albert Einstein College of Medicine, New York, NY, USA, ${ }^{2}$ Department of \\ Pathology, Case Western Reserve University, Cleveland, OH, USA, ${ }^{3}$ Department of Molecular Microbiology and Immunology, \\ Johns Hopkins Bloomberg School of Public Health, Baltimore, MD, USA
}

The adaptive humoral immune response is responsible for the generation of antimicrobial proteins known as immunoglobulin molecules or antibodies. Immunoglobulins provide a defense system against pathogenic microbes and toxins by targeting them for removal and/or destruction. Historically, antibodies have been thought to be composed of distinct structural domains known as the variable and constant regions that are responsible for antigen binding and mediating effector functions such as opsonization and complement activation, respectively. These domains were thought to be structurally and functionally

OPEN ACCESS

Edited by:

Amy Rasley,

Lawrence Livermore National

Laboratory, USA

Reviewed by:

Mirko Trilling,

University Duisburg-Essen; Essen

University Hospital, Germany

Dina Weilhammer,

Lawrence Livermore National Lab,

USA

${ }^{*}$ Correspondence:

Arturo Casadevall

acasade1@jhu.edu

Specialty section:

This article was submitted to

Microbial Immunology,

a section of the journal

Frontiers in Microbiology

Received: 21 October 2015

Accepted: 11 January 2016

Published: 04 February 2016

Citation:

Janda A, Bowen A, Greenspan NS and Casadevall A (2016) Ig Constant

Region Effects on Variable Region

Structure and Function.

Front. Microbiol. 7:22.

doi: 10.3389/fmicb.2016.00022 independent. Recent work has revealed however, that in some families of antibodies, the two regions can influence each other. We will discuss the body of work that led to these observations, as well as the mechanisms that have been proposed to explain how these two different antibody regions may interact in the function of antigen binding.

Keywords: immunoglobulin, isotype, constant region, variable region, structure, function

\section{INTRODUCTION}

Antibodies (Abs), or immunoglobulin (Ig) molecules are antimicrobial proteins that are secreted by B lymphocytes, and serve as critical participants in the adaptive immune response. The main function of Abs is to bind foreign molecules in the serum and other bodily fluids and, in most cases, label them for removal. This occurs through a form of molecular guilt by association, involving non-covalent binding of Abs to their antigens (Ag) and to cellular Fc receptors (FcRs). This removal is mediated by a variety of mechanisms associated with $\mathrm{Ab}$ function such as facilitation of phagocytosis, complement activation, and Ab dependent cellular cytotoxicity.

The Ig molecule consists of two polypeptide chains, a heavy $(\mathrm{H})$ and a light $(\mathrm{L})$ chain, each of which is composed of two regions, a constant region (C) and a variable region (V) (Figure 1). These chains form monomers which then combine into dimers, or higher-order oligomers to form a full Ig molecule. Both $\mathrm{C}$ and $\mathrm{V}$ regions contain domains from the $\mathrm{H}$ and $\mathrm{L}$ chains (Dreyer and Bennett, 1965). Functionally, the CH region confers effector properties such as complement binding, halflife length, interactions with FcRs, and the class, or isotype, of the Ig. In both humans and mice, there are four IgG, or $\gamma$-chain isotypes that are important for the identification and clearance of many peptide and polysaccharide Ags (Tonegawa, 1983). In contrast, the V region confers specificity to the Ig molecule by functioning as the direct contact between the Ig and its Ags.

Abbreviations: Ig, immunoglobulin; $\mathrm{Ab}$, antibody; $\mathrm{Ag}$, antigen; $\mathrm{mAb}$, monoclonal antibody; $\mathrm{CH}$, heavy chain constant region; $\mathrm{CL}$, light chain constant region; Fab, antigen binding fragment; Fc, crystallizable fragment; SPR, Surface Plasmon Resonance; ITC, Isothermal Calorimetry; ELISA, Enzyme-Linked Immunosorbent Assay. 


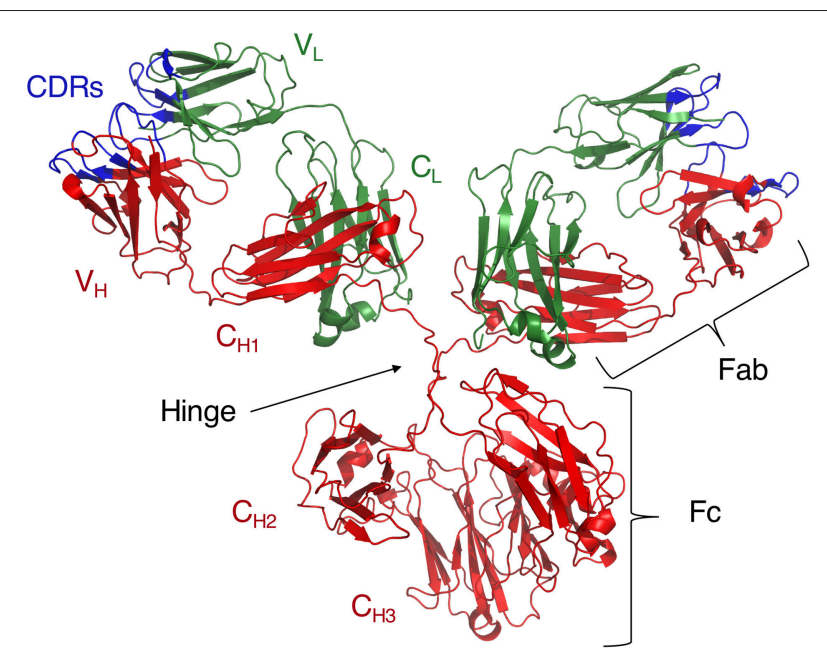

FIGURE 1 | Crystal structure of intact IgG 1 (PDB ID: 1IGY). Adapted from Harris et al. (1998).

\section{BACKGROUND}

Since the mid-twentieth century, the Ig molecule has been considered a bifunctional molecule consisting of two largely independent regions, a $\mathrm{V}$ region responsible for specificity and affinity, and a $\mathrm{C}$ region responsible for effector functions such as complement activation and interaction with FcRs. This view emerged from biochemical studies in the late 1950s, when Nobel laureate Rodney R. Porter used proteolytic digestion to cleave $\mathrm{Ab}$ molecules into fragments. These fragments eventually became known as the Ag binding fragment, or Fab, and the Fc fragment, because it could be easily crystallized (Porter, 1957; Porter and Press, 1957). One decade later, as the protein crystallography field progressed, X-ray studies of Fab fragments provided structural evidence consistent with the presumed functional separation of each adjacent $\mathrm{V}$ and $\mathrm{C}$ domain on both the $\mathrm{H}$ and $\mathrm{L}$ chain. For example, $\mathrm{V}_{\mathrm{L}}$ domains were found to be separated from their $\mathrm{C}_{\mathrm{H} 1}$ domain neighbors by long, disordered polypeptide chains that were interpreted as spacers both physically and functionally (Davies et al., 1975). This observation was confirmed by additional studies in the 1990's (Harris et al., 1997). The disordered nature of the spacers was interpreted as inconsistent with a tight structural connection where the $\mathrm{C}$ influenced the structure of the $\mathrm{V}$ and vice versa.

\section{STRUCTURAL AND BIOCHEMICAL EVIDENCE THAT SUGGESTS TWO INDEPENDENT DOMAINS}

The early hypotheses that the Fab region acted independently from the whole Ig were based on X-ray crystallographic studies of Fab and Fc fragments, Fab-hapten studies, and electron microscopy (EM) analysis of Ab-Ag complexes. Hapten studies provided additional support for the notion of two independent Ig regions as no evidence was found for structural changes in
Fab molecules upon hapten binding (Stryer and Griffith, 1965; Stryer, 1968; Yguerabide et al., 1970; Werner et al., 1972; Segal et al., 1974; Harris et al., 1997). EM studies also failed to show differences in Fab tertiary structure whether this region was bound to $\mathrm{Ag}$ alone or as part of a whole IgG (Feinstein and Rowe, 1965).

Furthermore, the presence of hypervariable regions, or complementarity determining regions (CDRs) in the $\mathrm{V}$ and not the $\mathrm{C}$ domains suggested the evolutionary importance of the specific conformation of each $\mathrm{V}$ region in $\mathrm{Ag}$ binding (Stryer and Griffith, 1965; Stryer, 1968; Yguerabide et al., 1970; Werner et al., 1972; Segal et al., 1974; Kabat et al., 1977; Chothia et al., 1989; Harris et al., 1997). Then, in the late 1970s, Tonegawa and collaborators showed that distinct genes encoding $\mathrm{V}$ and $\mathrm{C}$ regions were rearranged and combined to express the Ig molecule, providing a mechanism for the generation of $\mathrm{Ab}$ diversity while maintaining Ig effector function (Tonegawa, 1983). While V regions were shown to diversify during their adaptation to specific Ags, $\mathrm{C}$ regions maintained their structure, supporting the hypothesis that these two regions were functionally independent.

In the early 1980s, fluorescence studies by Oi et al. failed to show an interaction between $\mathrm{Ig} \mathrm{V}$ and $\mathrm{C}$ regions upon $\mathrm{Ag}$ binding (Oi et al., 1984). This negative evidence was nevertheless fully consistent with the evolving view of two independent domains. More recently, X-ray crystallographic studies of intact Igs have revealed a highly flexible hinge region described as a "loose tether" separating the Fab and Fc regions, allowing them to move freely with respect to one another (Saphire et al., 2002). We note that the classical view of two independent Ig domains emerged largely from the interpretation of negative data from a variety of structural techniques. However, there was also a certain elegance to the notion of two domains, one focused on binding and the other on downstream function, which appealed to the reductionist tenor of the times.

\section{EARLY CHALLENGES TO THE MODEL}

$\mathrm{Ab}-\mathrm{Ag}$ complexes are readily ingested by FcR-bearing cells in contrast to the minimal ingestion of free Ab. This observation raised the possibility that the greater affinity of $\mathrm{Ab}-\mathrm{Ag}$ complexes for $\mathrm{FcRs}$ was the result of a structural change in the $\mathrm{Ab}$ molecule upon binding Ag. In 1976, Huber et al. proposed an allosteric Ig model whereby Ag binding triggered a signal that traveled from the $\mathrm{V}$ to the $\mathrm{C}$ regions (Huber et al., 1976). This signal was thought to run from the $\mathrm{V}$ domain along conserved residues involved in inter-chain and inter-domain contacts to reach the $\mathrm{C}$ domain and cause a structural change that could enhance affinity for FcRs. In their final model, based on X-ray crystallographic data as well as molecular dynamics simulations of a full IgG molecule, they emphasized that all longitudinal contacts were closed. They stated that this resulted in a rigid structure where $\mathrm{Fab}_{2}$ bending was inhibited by $\mathrm{CH}_{\mathrm{H}}-$ $\mathrm{C}_{\mathrm{H} 2}$ interactions. They further suggested that Ag binding caused overall Ig stiffening. This stiffening was thought to occur because the flexible hinge region allowed for their hypothesized $\mathrm{C}_{\mathrm{H} 1}-$ $\mathrm{C}_{\mathrm{H} 2}$ contacts, resulting in a rigid, T-shaped, Ig (Huber et al., 
1976). These inferences suggested that $\mathrm{C}_{\mathrm{H} 1}-\mathrm{C}_{\mathrm{H} 2}$ contacts exist and are critical to Ag binding. They based their modeling studies of X-ray crystallographic IgG data on the hypotheses that Igs had both segmental rigidity and overall flexibility, and that free Fab molecules were rigid (Huber et al., 1976). These inferences were in turn based on the earlier Fab-hapten binding studies (Stryer and Griffith, 1965; Stryer, 1968; Yguerabide et al., 1970; Werner et al., 1972; Segal et al., 1974).

During this time it was also suggested that Ag binding may result in $\mathrm{Ab}$ conformational changes that lead to complex formation, which are in turn readily identified by macrophage FcR for uptake (Shinomiya and Koyama, 1976). This view was based on older evidence that Ab-Ag complexes were cleared from the serum at much faster rates than free $\mathrm{Ab}$ (Benacerraf et al., 1959). However, the view of an allosteric change in the Ab molecule that facilitated the interaction with FcR did not gain favor and was supplanted by the explanation that the greater affinity of $\mathrm{Ag}-\mathrm{Ab}$ complexes was due to cross-linking of FcRs. Again, the allosteric view was abandoned largely due to negative data, while cross-linking of FcRs was a demonstrable effect that triggered signal transduction and explained increased binding of $\mathrm{Ag}-\mathrm{Ab}$ complexes on the basis of increased avidity without the necessity of conformational changes.

By the 1990's the notion that Ig molecules comprised two independent non-interacting domains had largely taken root and become immunological dogma. However, several studies reported observations that seemed at odds with the hypothesis of one molecule with two independent functional regions. Over the past decade a new notion has emerged that views both Ig regions as interacting and functionally connected. These observations have also shown that $\mathrm{V}-\mathrm{C}$ interactions may vary between isotype families, suggesting that the basic model of Ig structure-function needs to be reconsidered and revised.

\section{ISOTYPE SWITCHING GENERATES VARIANTS WITH DIFFERENT PROPERTIES}

Beginning in the early 1990s and continuing into the first decade of the twenty-first century, at least eight independent groups have reported that isotype switching is associated with altered specificity despite conservation of $\mathrm{V}$ region sequence (Kato et al., 1991; Pritsch et al., 1996; McLean et al., 2002; Torres et al., 2005, 2007a; Dam et al., 2008; Torres and Casadevall, 2008; Casadevall and Janda, 2012; Tudor et al., 2012; Xia et al., 2012; Hovenden et al., 2013; Dodev et al., 2015). This effect has been reported for $\operatorname{IgM}, \operatorname{IgG}, \operatorname{IgE}$ and $\operatorname{IgA}$ with both protein and nucleic acid Ags, using a variety of techniques such as ELISA, ITC, and SPR (Table 1).

An early study from Kato et al., found significant changes in $\mathrm{Ag}$ binding when comparing murine isotype Fabs with identical $\mathrm{V}_{\mathrm{L}}, \mathrm{C}_{\mathrm{L}}$, and $\mathrm{V}_{\mathrm{H}}$ sequences as well as an Fab with a complete $\mathrm{C}_{\mathrm{H} 1}$ domain deletion mutant (Kato et al., 1991). They used ${ }^{13} \mathrm{C}$ Nuclear Magnetic Resonance (NMR) as a spectroscopic probe of both lateral and longitudinal domain-domain Fab interactions upon $\mathrm{Ag}$ binding in a group of murine Fabs derived from $\operatorname{IgG}_{1}$, $\mathrm{IgG}_{2 \mathrm{a}}$, and $\mathrm{IgG}_{2 \mathrm{~b}}$ isotypes. They were also able to probe chemical shifts directly responsible for Ag binding within the CDR3 loop. They found isotype differences in chemical shifts in the CDR3 region, or paratope as well as other, non-Ag binding residues throughout the Fabs. This work implied that subtle chemical shifts in both the paratope and other, more distant residues occurred within Fab molecules upon Ag binding, and that these shifts could vary depending on isotype (Kato et al., 1991).

Another study, which appeared shortly afterward, used human monomeric Fabs derived from $\operatorname{IgA}_{1}$ and $\operatorname{IgG}_{1}$ in Surface Plasmon Resonance (SPR) experiments with a monovalent Ag. Significant differences in $\mathrm{Ab}-\mathrm{Ag}$ association rate constants between the Fabs studied were found (Pritsch et al., 1996). In this work the authors suggested that in a particular mAb, affinity maturation could be achieved through class switching, suggesting a role for the $\mathrm{C}_{\mathrm{H} 1}$ domain in allosterically influencing the Ag binding site (Pritsch et al., 1996). The same group, in 2000, isolated four human IgG mAbs, three of which had identical $V_{L}$ and $V_{H}$ domains. Among this set, the $\operatorname{IgA}_{1}$ and $\operatorname{IgG}_{1}$ isotypes manifested significant differences in affinity, though they bound to the same Ag motif. They then created $\operatorname{IgG}_{1}$ and IgM from the $\operatorname{Ig} A_{1} m A b$, and found that the IgM bound to its epitope with the same affinity as the parental $\operatorname{Ig} A_{1}$, whereas the $\mathrm{IgG}_{1}$ had significantly lower affinity as measured by SPR. This result was reproducible using Fabs derived from $\operatorname{IgG}_{1}$ and IgA (Pritsch et al., 2000). Consequently, they hypothesized that conformational changes in Fab molecules were occurring upon Ag binding, and were most likely being transferred through the elbow angle. Furthermore, Pritsch et al. were able to create a model of the $\mathrm{V}_{\mathrm{H}}-\mathrm{C}_{\mathrm{H} 1}$ interface of their $\operatorname{IgA} \mathrm{A}_{1}$ and $\operatorname{IgG}_{1}$ using X-ray crystallographic structures derived from homologous proteins, and found that one of the $\mathrm{C}_{\mathrm{H} 1}$ loops was directly involved in $\mathrm{V}_{\mathrm{H}}-\mathrm{C}_{\mathrm{H} 1}$ contacts. Their model also showed that this loop had a different conformation for each isotype (Pritsch et al., 2000). This work supports the hypothesis that the $C_{H 1}$ domain has an allosteric role in Ag binding and may also be transmitting structural signals to the rest of the Ig as suggested by Huber et al.'s earlier work.

McLean et al. made chimeric mAb isotypes (murine $\mathrm{V}$ region with human $\operatorname{IgA}_{1}$, IgG $1 / 2 / 3 / 4$, and $\operatorname{IgM} C$ regions) that showed differences in fine specificity from the parent murine $\mathrm{Ab}$. Furthermore, they saw differences between the various chimeric Abs upon binding monovalent and multivalent Ags, as well as differences in their binding location to a microbial capsule (McLean et al., 2002). Further SPR studies using this family of $\mathrm{mAbs}$ compared the intact murine $\mathrm{IgG}_{1}$ with its chimeric form as well as its deglycosylated form. These studies revealed that glycosylation did not alter Ag binding kinetics and there were no significant differences in $\mathrm{Ag}$ binding between the original $\mathrm{mAb}$ and its murine-human chimeric form (Torres et al., 2007a). However, it is unclear whether $\mathrm{C}$ region glycosylation may play a role in the Ag binding of other families of isotypes, as this has not been thoroughly studied.

A series of studies with the 3E5 family of murine isotypes to Cryptococcus neoformans polysaccharide also identified significant changes in isotype specificities and affinities. Using both multi and monovalent Ags, and ELISA, SPR, and Isothermal Titration Calorimetry (ITC) studies, the authors measured 
TABLE 1 | Summary of studies finding mAb isotype differences in Ag binding.

\begin{tabular}{|c|c|c|}
\hline Year & Finding & References \\
\hline 1991 & $\begin{array}{l}\text { When } \mathrm{C}_{\mathrm{L}} \text { and } \mathrm{C}_{\mathrm{H} 1} \text { residues were substituted in } \mathrm{mlgG}_{1}, 2 \mathrm{a} \text {, and } 2 \mathrm{~b} \text { Fab isotypes, differences in Ag binding using } \\
\text { HSQC NMR were seen. }\end{array}$ & Kato et al., 1991 \\
\hline 1993 & $\begin{array}{l}\text { Murine } \operatorname{lgG}_{3} \text { isotype was shown to self-aggregate through non-covalent } F_{c}-F_{c} \text { interactions, thereby causing } \\
\text { differences in affinity for and binding to multivalent Ags as compared to its } \operatorname{lgG}_{1} \text { isotype. }\end{array}$ & $\begin{array}{l}\text { Greenspan and Cooper, } \\
1993\end{array}$ \\
\hline 1996 & hlgA1, hlgG 1 , hlgG 2 , and $h_{l g G_{4}}$ isotypes were found to have different KD constants using SPR. & Pritsch et al., 2000 \\
\hline \multirow[t]{2}{*}{2002} & $\begin{array}{l}\mathrm{mlgG}_{1} \text {, and mouse-human chimeras (murine V-region with human constant regions 1, 2, 3, 4, M, and A1) were } \\
\text { seen to have different Ag binding profiles by ELISA and Immunofluorescence. }\end{array}$ & $\begin{array}{l}\text { McLean et al., 2002; Torres } \\
\text { et al., 2007a }\end{array}$ \\
\hline & $\begin{array}{l}\text { SPR studies showed no changes in thermodynamics upon deglycosylation of mlgG } 1 \text {, as well as significant } \\
\text { differences between mlgG1 and its chimera. }\end{array}$ & \\
\hline 2005-2015 & $\begin{array}{l}\text { mlgG }_{1}, 2 \mathrm{a}, 2 \mathrm{~b} \text {, and } 3 \text { isotypes were shown to have different Ag binding profiles and kinetics using ELISA, } \\
\text { Immunofluorescence, ITC and SPR. They were further found to have differences in Trp fluorescence, CD } \\
\text { spectroscopy with multivalent Ag, and chemical shifts by NMR when binding to a monovalent Ag. Monovalent } \\
\text { peptide Ag cleavage assays revealed different abilities to cleave Ag as well as different rates of cleavage between } \\
\text { the isotypes that cleaved. }\end{array}$ & $\begin{array}{l}\text { Torres et al., 2005, 2007b; } \\
\text { Janda and Casadevall, } \\
\text { 2010; Casadevall and } \\
\text { Janda, 2012; Janda et al., } \\
\text { 2012, 2015; Eryilmaz et al., } \\
2013\end{array}$ \\
\hline 2012 & $\begin{array}{l}\text { A human } \operatorname{lgG}_{1} \text { and its IgGA2 isotype were found to have differences in HIV-1 gp41 epitopes as well as Ag affinities } \\
\text { measured by ELISA. }\end{array}$ & Tudor et al., 2012 \\
\hline 2012-2013 & $\begin{array}{l}\mathrm{mlgG}_{1}, 2 \mathrm{a}, 2 \mathrm{~b} \text {, and } 3 \text { isotypes displayed differences in affinity to the same Ag using SPR methods, as well as } \\
\text { isotype differences in Trp fluorescence and CD spectroscopy upon Ag binding. }\end{array}$ & Xia et al., 2012, 2013 \\
\hline 2013 & $\mathrm{mlgG}_{1}, 2 \mathrm{a}, 2 \mathrm{~b}$, and 3 isotypes were found to have different affinities to Ag using SPR. & Hovenden et al., 2013 \\
\hline 2013 & Human $\operatorname{lgG}_{1}$ and IgA2 found to have different affinities for HIV-1 Env Ag by SPR. & Tomaras et al., 2013 \\
\hline 2015 & Human IgG, IgA, IgE isotypes compared by SPR, found to have different Ag affinities. & Dodev et al., 2015 \\
\hline
\end{tabular}

significant differences in binding among the four IgG isotypes (Torres et al., 2005, 2007b; Dam et al., 2008). A monovalent peptide Ag mimetic was used for ELISA binding studies, SPR, and ITC studies. SPR was done with Fabs derived from the 3E5 murine IgG isotype set to isolate the $\mathrm{V}$ region and a single $\mathrm{C}$ region-the $\mathrm{C}_{\mathrm{H} 1}$. Among the isotypes, the $\operatorname{IgG}_{1} \mathrm{Fab}$ showed the most favorable binding parameters. This implied that differences in specificity among the isotypes were potentially due to differences in the $\mathrm{C}_{\mathrm{H} 1}$ region alone (Torres et al., 2007b). ITC studies done with the 3E5 family using full IgG molecules and the P1 peptide Ag, confirmed a 2:1 binding stoichiometry of peptide:Ab as well as significantly different association constants between all four isotypes (Dam et al., 2008).

In 2012, Tudor et al. reported increased monovalent Ag specificity and binding affinity when switching an anti-HIV-1 human $\operatorname{IgG}_{1}$ to a monomeric IgA2. They also found altered epitope specificity and increases in anti-HIV-1 activity assays, indicating significant changes to the Ig paratope (Tudor et al., 2012). A study by Crespillo et al., with the same family of mAbs, compared ITC binding parameters between the Fab and whole IgG of human 2F5. Their results showed significant differences in binding affinities between the different forms of $\mathrm{Ab}$ and monomeric peptide Ag epitopes, with highest affinities achieved with whole IgG (Crespillo et al., 2014). This adds to the observation that in this case, in addition to the $\mathrm{C}_{\mathrm{H} 1}$ region, the $\mathrm{C}_{\mathrm{H} 2}$ and/or $\mathrm{C}_{\mathrm{H} 3}$ regions may also be playing a strong role in $\mathrm{Ag}$ binding.

More recently, Xia et al. expanded this observation to include anti-nuclear mAbs. They discovered that a family of antiDNA murine mAb IgG isotypes had significant differences in binding affinities by SPR. They also studied Trp fluorescence and circular dichroism with these isotypes and observed changes upon Ag binding that were isotype dependent (Xia et al., 2013).

For a set of Abs binding to the Bacillus anthracis capsule class-switching from the original $\operatorname{IgG}_{3}$ to $\operatorname{IgG}_{1}, \operatorname{IgG}_{2 \mathrm{a}}$, and $\operatorname{IgG}_{2 b}$ isotypes resulted in a loss of protection, affinity and a change in mAb binding to its capsular Ag (Hovenden et al., 2013). Hovenden et al. further determined that switching the $\mathrm{C}_{\mathrm{H} 1}$ region of the protective isotype with highest affinity $\left(\operatorname{IgG}_{3}\right)$, for the $\mathrm{C}_{\mathrm{H} 1}$ region from a non-protective isotype with the lowest affinity $\left(\operatorname{IgG}_{2 b}\right)$, showed no loss of affinity or protection. However, swapping the $\mathrm{C}_{\mathrm{H} 2}$ or $\mathrm{C}_{\mathrm{H} 3}$ regions from the $\operatorname{IgG}_{2 b}$ to the $\mathrm{IgG}_{3}$, reduced affinity and resulted in a loss of protection, more so with the $\mathrm{C}_{\mathrm{H} 2}$ region (Hovenden et al., 2013). This contrasts with earlier studies that reported similar binding differences between Fab fragments and whole IgG, suggesting an allosteric role for the $\mathrm{C}_{\mathrm{H} 1}$ domain (Yuan et al., 1995, 1998; Torres et al., 2007b). Furthermore, Hovenden et al. used a monovalent peptide to measure fluorescence perturbation as an indication of intrinsic affinity, and found significant differences among the isotypes. Although they could not exclude a contribution from Fc-Fc interactions, there was evidence that other factors must also be contributing to the observed changes in affinity (Hovenden et al., 2013). Using their family of isotypes, they were also able to exclude the hypothesis that as flexibility of the hinge region increases, Ag binding affinity increases. This hypothesis had been suggested by Morelock et al. to explain how isotype could influence human mAb affinity (Morelock et al., 1994; Tomaras et al., 2013). Hovenden et al. further hypothesized that the contributions from the $\mathrm{C}$ region in this family of $\mathrm{mAb}$ isotypes may be due to (i) glycosylation, although de-glycosylation of 
their $\mathrm{IgG}_{3}$ did not change its functional affinity, (ii) possible $\mathrm{C}_{\mathrm{H} 2}$ influence on $\mathrm{mAb}$ charge, or (iii) $\mathrm{C}$ region effects on the chemical and/or electrostatic environment of the paratope. These studies shed light on the different behaviors of different families of $\mathrm{mAb}$ isotypes and the need to further investigate and understand how $C$ regions affect paratope properties and how this may differ between different $\mathrm{mAb}$ families.

Recently, several studies have identified additional instances where Abs with identical $\mathrm{V}$ regions differing in isotype manifest differences in Ag binding. A group studying human anti-HIV-1 Env mAbs identified that an $\operatorname{IgA}_{2}$ and $\mathrm{IgG}_{1}$ sharing the same $\mathrm{V}$ region had significantly different Env $\mathrm{Ag}$ binding affinities using SPR studies. In fact, they found that the $\operatorname{IgA}_{2}$ bound one Ag strain with 2.9-fold higher magnitude and affinity and another Ag strain with 40 -fold greater affinity than the $\mathrm{IgG}_{1}$ isotype (Tomaras et al., 2013). Another group studying the Phl p7 grass pollen allergen generated a full panel of human IgG and IgA isotypes and found subtle but significant differences in binding rates using SPR. They observed the greatest differences in both on- and off-rate constants to be about three-fold, which canceled out to give an overall affinity range of 250-570 picomoles (pM) (Dodev et al., 2015).

In addition to the various examples of $\mathrm{V}$ region-identical Igs exhibiting specificity differences, it is important to note that several studies have reported $\mathrm{V}$ region-identical Igs with no changes in specificity. Although the failure to detect changes could be the result of insufficient sensitivity in the assays done, it is possible that the phenomenon of $\mathrm{C}$-mediated changes in specificity and affinity is associated with some $\mathrm{V}$ regions and not others. Consequently we compared unique $\mathrm{V}_{\mathrm{H}}$ and $\mathrm{V}_{\mathrm{L}}$ sequences from 24 Igs with $\mathrm{V}$ region-identical isotype switch variants compiled from the literature (Table 2). An analysis of the sequence similarities and germline gene hits for these Igs shows that these appear to group phylogenetically, consistently with the notion that certain $\mathrm{V}$ region gene families may differ in being permissive or non-permissive of specificity changes following class switching (Figure 2). It is interesting to note that all of the human lambda $V_{L}$ Igs were non-permissive. With the small number of Ig sequences available for this analysis, no firm conclusions can be made and more examples will be needed to confirm a $\mathrm{V}$ region germline basis for $\mathrm{C}$ domain-mediated specificity changes. It will also be useful to compare the structures of Igs with very similar $\mathrm{V}$ regions that differ in specificity to determine whether they are permissive of specificity changes, such as $V_{L}$ sequences 6,8 , and 11 in Table 2. Furthermore, the combination of specific $\mathrm{V}_{\mathrm{H}}$ and $\mathrm{V}_{\mathrm{L}}$ genes is another potential variable for $\mathrm{C}$ domain-mediated specificity changes since it is conceivable that even for permissive $\mathrm{V}$ regions that expression of this effect requires combination with certain $\mathrm{C}$ regions. In this regard it is noteworthy that different $\mathrm{C}$ regions combined with the same $\mathrm{V}$ region manifested differences in the magnitude of the changes observed (Janda et al., 2015).

These studies necessitate expanding the role for isotype class switching to a new role where it contributes to the generation of Ig diversity. A recent review by Sela-Culang et al., suggests that changes in $\mathrm{C}$ regions or their conformations may lead to structural $\mathrm{C}$ domain rearrangement relative to other $\mathrm{C}$ and
$\mathrm{V}$ domains. They suggested that this could re-shape the Ag binding site and as such could be considered as a mechanism for generating Ab diversity (Sela-Culang et al., 2013). This is further supported by the hypothesis that the conformational diversity of $\mathrm{Abs}$ is directly linked to $\mathrm{Ab}$ multispecificity and supports the role of a single sequence (i.e., V region) adopting multiple structures and functions (Reitan and Hannestad, 1995, 2001; Lange et al., 1996; James and Tawfik, 2003). Since the mechanisms of isotype switching and somatic mutation share some of the same proteins this notion has the elegance of bringing together these two processes within the same molecular pathways. Isotype class switching has further implications for primary and secondary B cell responses, idiotype reactivity and immunogenicity. Also, the observation that Ig class switching can result in reactivity for self Ags despite identical $\mathrm{V}$ regions suggests that this phenomenon may be implicated in the appearance of certain pathological autoimmune responses (Torres et al., 2007b). An understanding of how $\mathrm{C}$ regions affect $\mathrm{Ab}$ paratope is important for the development of therapeutic mAbs (Nosanchuk, 2013). At least two mechanisms have been proposed for this effect: (i) $\mathrm{C}$ region-mediated allosteric effects on $\mathrm{V}$ region paratope structure before and/or during Ag binding (Huber et al., 1976; Janda et al., 2012) and (ii) subclass-mediated differences in functional affinity leading to the differential recognition of multivalent epitope arrays (Cooper et al., 1993). A plausible mechanism on the molecular level for the first of these effects involves $\mathrm{C}$-mediated structural constraints on $\mathrm{V}$ region structure that affect the conformation of the Ig paratope. In contrast, $\mathrm{C}$ region glycosylation has thus far not been shown to contribute to this phenomenon (Torres et al., 2007a,b; Hovenden et al., 2013).

\section{REGION MODIFICATION OF SPECIFICITY THROUGH INCREASED FUNCTIONAL AFFINITY}

In 1987, Greenspan et al. reported that murine $\operatorname{IgG}_{3}$ mAbs specific for the cell wall polysaccharide of Streptococcus pyogenes were able to bind cooperatively to whole bacteria treated with a protease to make the relevant epitopes accessible. The Fc regions were found to be required for this enhanced binding. Subsequently, Cooper et al. (1991) demonstrated that $\operatorname{IgG}_{3}$ bound more strongly to treated (as above) group A streptococcal bacteria than $I_{g G}$ and $I_{g G}$ switch variants confirmed to be $\mathrm{V}$ domain-identical by cDNA sequencing (Greenspan et al., 1987; Cooper et al., 1991).

Cooper et al. (1993) further demonstrated that in this system the $\operatorname{IgG}_{3} \mathrm{mAb}$ exhibited a different pattern of binding to three strains of group A streptococci displaying the relevant epitope at different densities than the $\operatorname{IgG}_{1}$ or $\operatorname{IgG}_{2 b}$ intact Ig molecules or $\mathrm{F}\left(\mathrm{ab}^{\prime}\right)_{2}$ fragments of $\mathrm{IgG}_{3}$. While the $\mathrm{IgG}_{1}$ and $\operatorname{IgG}_{2 \mathrm{~b}}$ Abs and the $\operatorname{IgG}_{3} \mathrm{~F}\left(\mathrm{ab}^{\prime}\right)_{2}$ fragments bound best to the streptococcal strain with the highest epitope density, the $\operatorname{IgG}_{3} \mathrm{Ab}$ bound best to the strain with intermediate epitope density. Additional experiments verified that despite these differences in binding to multivalent Ags, the three Abs (IgG, $\operatorname{IgG}_{1}$, and $\operatorname{IgG}_{2 \mathrm{~b}}$ ) bound to monovalent $\mathrm{Ag}$ or 
TABLE 2 | Unique antibodies with variable-region-identical isotype-switch variants and identifiable amino acid sequences.

\begin{tabular}{|c|c|c|c|c|c|c|}
\hline seqID & Antibody & Organism & Permissive & Top VL gene & Top VH gene & References \\
\hline 2 & HGAC 39.G3, G1, G2b & Murine & Y & IGKV2-109*04 & IGHV6-301 & $\begin{array}{l}\text { Greenspan and Cooper, } \\
1993\end{array}$ \\
\hline 4 & F105 mAb anti-gp120 G1, G3 & Human & $\mathrm{N}$ & IGKV3-20*01 & IGHV4-59*01 & Marasco et al., 1992 \\
\hline 5 & anti-tubulin mAb & Human & Y & IGKV2-28*01 & IGHV3-73*02 & Pritsch et al., 2000 \\
\hline 6 & IF6, 1E1, 2E12 mAbs anti-O6 LPS & Murine & $\mathrm{N}$ & IGKV1-110*01 & IGHV1S13701 & Pollack et al., 1995 \\
\hline 8 & 18B7 anti-GXM & Murine & Y & IGKV1-110*01 & IGHV5-6-2*01 & Mukherjee, 1992 \\
\hline 10 & F425 mAb anti-gp140 G2, G1, G3, A & Human & Y & IGKV1D-33*01 & IGHV3-64*01 & Liu et al., 2003 \\
\hline 11 & 3E5 anti-GXM & Murine & Y & IGKV1-110*01 & IGHV5-6-2*01 & Mukherjee, 1992 \\
\hline 14 & F240 mAb anti-HIV G1, G3, G4 & Human & $\mathrm{N}$ & IGKV4-1*01 & IGHV3-11*04 & Cavacini et al., 1998 \\
\hline 15 & F598 mAb anti-PNAG G2, G1 & Human & $\mathrm{N}$ & IGLV4-69*01 & IGHV4-59*01 & Kelly-Quintos et al., 2006 \\
\hline 16 & F628 mAb anti-PNAG G2, G1 & Human & $\mathrm{N}$ & IGLV4-69*01 & IGHV4-59*01 & Kelly-Quintos et al., 2006 \\
\hline 17 & F630 mAb anti-PNAG G2, G1 & Human & $\mathrm{N}$ & IGLV4-69*01 & IGHV1-18*04 & Kelly-Quintos et al., 2006 \\
\hline 18 & 2G8, $1 \mathrm{E} 12$ mAbs anti-beta glucan G2b, M & Murine & Y & IGKV1-133*01 & IGHV1-9*01 & Torosantucci et al., 2009 \\
\hline 20 & $12.8 \mathrm{mAb}$ anti-pfMSP1 & Murine & Y & IGKV4-70*01 & IGHV9-1*02 & Porter and Press, 1957 \\
\hline 21 & 12.10 mAb anti-pfMSP1 & Murine & Y & IGKV6-17*01 & IGHV1S81*02 & Porter and Press, 1957 \\
\hline 23 & 2F5 bNAb anti-HIV1 G1, A2 & Human & Y & IGKV1-13*02 & IGHV2-5*02 & Kunert et al., 1998 \\
\hline 24 & C1 mAb anti-pfMSP1 G1, G2a, G2b, G3 & Murine & $\mathrm{N}$ & IGKV8-28*01 & IGHV1-8501 & $\begin{array}{l}\text { Adame-Gallegos et al., } \\
2012\end{array}$ \\
\hline 27 & IgA1 and lgG1 crystallized Fabs & Human & Y & IGKV2-28*01 & IGHV3-73*02 & Correa et al., 2013 \\
\hline 28 & F24F2 mAb anti- $\gamma$ dPGA B. anthracis G3, G1, G2a, G2b & Murine & Y & IGKV1-135^01 & IGHV10-1*02 & Kozel et al., 2007 \\
\hline 29 & F26G3 mAb anti- $\gamma$ dPGA B. anthracis G3, G1, G2a, G2b & Murine & Y & IGKV1-135*01 & IGHV10-1*02 & Kozel et al., 2007 \\
\hline 30 & PL9-11 mAb G3, G1, G2a, G2b & Murine & Y & IGKV8-28*02 & IGHV5-9*04 & Xia et al., 2013 \\
\hline 34 & Fl6 bNAb anti-HA stalk G1, G2a, DA265 & Human & $\mathrm{N}$ & IGKV4-1*01 & IGHV3-30-3*02 & Porter, 1957 \\
\hline 35 & PY102 mAb anti-HA head G1, G2a, DA265 & Murine & $\mathrm{N}$ & IGKV8-28*01 & IGHV5-9*04 & Zaghouani et al., 1989 \\
\hline 41 & PGT121 & Human & $\mathrm{N}$ & IGLV3-21*02 & IGHV4-4*08 & Walker et al., 2011 \\
\hline 45 & 20B1 G1, G2a, G2b & Murine & $\mathrm{N}$ & IGKV9-124*01 & IGHV9-4*02 & French et al., 1957 \\
\hline
\end{tabular}

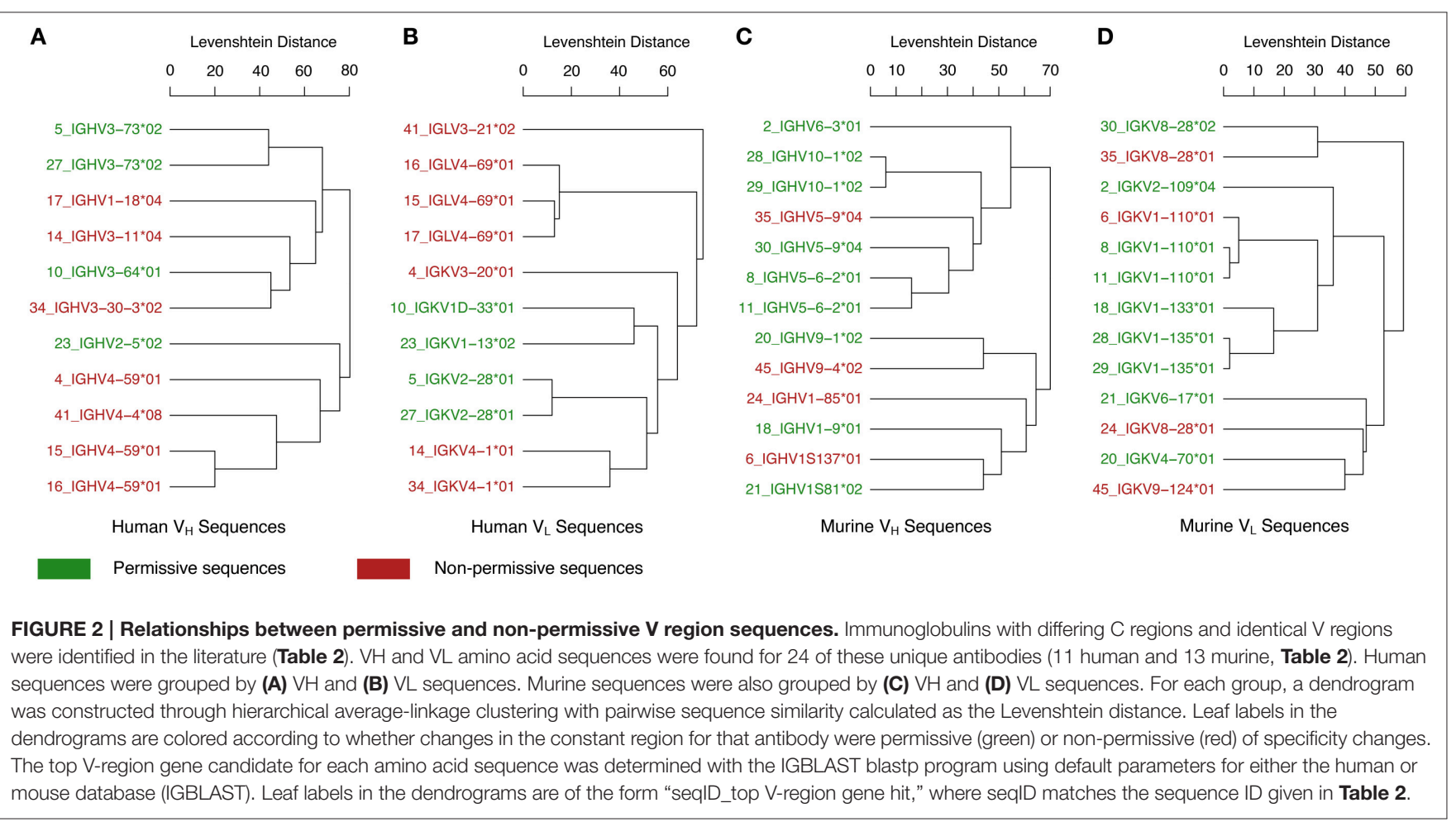


multiple rat anti-idiotypic mAbs comparably (Cooper et al., 1993).

Thus, in spite of identical $\mathrm{V}$ domain amino acid sequences and ability to bind monovalent hapten, the $\mathrm{IgG}_{3} \mathrm{Ab}$ discriminated among multivalent antigens differently than the $\mathrm{IgG}_{1}$ or $\mathrm{IgG}_{2 \mathrm{~b}}$ Abs (i.e., exhibited different multivalent fine specificities). Additional conclusions drawn by the authors are that epitope density and $\mathrm{H}$ chain $\mathrm{C}$ region structural differences can contribute to differences in multivalent binding among IgG subclasses. Analysis of this Ab-Ag system with SPR revealed that the stronger binding of the cooperative $\mathrm{IgG}_{3} \mathrm{Ab}$, in comparison to the non-cooperative $\operatorname{IgG}_{1}$ and $\operatorname{IgG}_{2 b}$ Abs, was associated with both greater on rates and slower off rates, consistent with the hypothesis that non-covalent $\mathrm{Fc}-\mathrm{Fc}$ interactions mediated the cooperativity of the IgG $3 \mathrm{Ab}$ (Cooper et al., 1994).

Also in 1993, Schreiber et al. generated an $\mathrm{IgG}_{3}$ isotype switch to a murine $\operatorname{IgG}_{1} \mathrm{mAb}$ against a Pseudomonas aeruginosa polysaccharide $\mathrm{Ag}$, as well as an $\mathrm{IgG}_{1}$-derived $\mathrm{F}(\mathrm{ab})_{2}$. These authors found that the intact $\mathrm{IgG}_{3}$ molecule had stronger binding affinities than the $\mathrm{V}$ domain identical $\mathrm{IgG}_{1}$ Ab to the $P$. aeruginosa $\mathrm{Ag}$, and they hypothesized that this better binding was most likely due to the greater functional affinity (i.e., multivalent affinity or avidity) of the murine $\mathrm{IgG}_{3} \mathrm{Ab}$ (Schreiber et al., 1993).

In roughly the same time period, Izui and colleagues published a number of papers focused on murine $\operatorname{IgG}_{3}$ cryoglobulins in autoimmune disease models that reported data consistent with the results of Greenspan and his associates. For example, Fulpius et al. studied a pathogenic murine $\operatorname{IgG}_{3} \mathrm{mAb}$ derived from a MRL/MpJ-lpr/lpr mouse and exhibiting cryoglobulin and rheumatoid factor activity for $\operatorname{IgG}_{2 \mathrm{a}}$ along with a $\mathrm{V}$ domainidentical switch variant $\mathrm{Ab}$ of the $\operatorname{IgG}_{1}$ subclass. The $\operatorname{IgG}_{1} \mathrm{Ab}$ lacked the cryoglobulin activity and displayed at least a $90 \%$ reduction in ability to bind to $\operatorname{IgG}_{2 a} \mathrm{Fc}$ regions (Fulpius et al., 1993).

Another group with similar results on isotype differences in avidity during this time used a set of chimeric mAbs (murine $\mathrm{V}$ region, human $\mathrm{C}$ region) against both monovalent and bivalent intercellular adhesion molecule 1 . They used ELISA competition studies with whole $\mathrm{mAb}$ as well as chimeric and murine Fab fragments. Though full-length mAbs showed differences in competition ELISA, their murine and chimeric Fab counterparts had equivalent binding constants, indicating that any differences in whole $\mathrm{mAb}$ were due to differences in avidity, and not monovalent affinity (Morelock et al., 1994).

\section{REGION MODIFICATION OF SPECIFICITY THROUGH ALLOSTERIC CHANGES}

Circular dichroism studies done on a family of murine IgGs to C. neoformans polysaccharide showed that the $\mathrm{C}$ and $\mathrm{V}$ regions are structurally coupled and affect each other during Ag binding (Janda and Casadevall, 2010). This was followed by tryptophan fluorescence studies of the same family of murine IgG Abs which showed different changes in electrical properties of Ig Fab Trp molecules some of which are in the paratope, upon Ag binding.
NMR studies of the same group of Igs further expanded the notion by showing differences in the chemical environments of their paratopes, as well as IgE and IgA isotypes. Finally, X-ray crystallographic studies and molecular modeling of these Igs identified structural differences that occur mainly in the hinge angles among Fab molecules of the $\mathrm{IgG}_{1}$ and $\mathrm{IgG}_{3}$ isotypes (Janda et al., 2012, 2015).

In 2003 Adachi et al. used molecular dynamics simulations to compare the crystal structures of a murine $\mathrm{mAb}_{\mathrm{IgG}} \mathrm{Fab}$ alone, Fab in complex with its hen egg lysozyme (HEL) Ag and the Fv ( $\mathrm{V}$ regions only) in complex with HEL (Adachi et al., 2003). The Fv-HEL complex was found to have a dissociation constant one order of magnitude lower than that of the Fab-HEL complex (Lavoie et al., 1992). In addition, Adachi et al. identified significant differences in the structures including (i) 18 water molecules in Fv-HEL interface, while the Fab-HEL interface had only one, (ii) the second upper loop in the $\mathrm{C}_{\mathrm{L}}$ domain in the Fab light chain (UL2- $\mathrm{C}_{\mathrm{L}}$ ) showed large conformational fluctuations when compared to the crystal structure of Fab alone. The difference in water molecules in the interface may represent a much tighter interaction for the Fab-HEL complex, which may be essential for HEL binding and could explain the differences in dissociation factors. The authors hypothesized that removal of the $\mathrm{C}$ domains in the $\mathrm{Fv}$ molecule may result in imperfect complementarity between $\mathrm{Ab}$ and $\mathrm{Ag}$, and thus lead to an increase in water molecules between paratope and epitope (Adachi et al., 2003). Furthermore, the UL2- $C_{L}$ region, which is highly conserved in human and murine light chains, was previously predicted to have unique fluctuations corresponding with Ag binding (Kabat et al., 1975). These new studies indicate that the UL2- $\mathrm{C}_{\mathrm{L}}$ fluctuations may be playing an important role in allosteric mediation of paratope-epitope interactions (Adachi et al., 2003).

In 2013, Xia et al. found that anti-DNA mAb V-domain identical switch variants from a murine SLE autoantibody model have different changes in secondary structure upon Ag binding, confirming coupling of the $\mathrm{C}$ and $\mathrm{V}$ regions. In addition, they found significant differences in histone and kidney Ag binding profiles using SPR, and different changes in Trp fluorescence upon Ag binding. Moreover, these differences were associated with significant differences in renal pathogenicity and survival studies that included in-vivo Ab administration (Xia et al., 2013).

$\mathrm{X}$-ray crystallographic studies of $\mathrm{V}$ region identical human Fab from $\operatorname{IgA}_{1}$ and $\operatorname{IgG}_{1}$ by Correa et al. reveal greater rigidity in the $\mathrm{C}_{\mathrm{H} 1}-\mathrm{C}_{\mathrm{L}}$ and $\mathrm{C}_{\mathrm{H} 1}-\mathrm{V}_{\mathrm{H}}$ interfaces in the $\operatorname{IgA}_{1}$ structure, suggesting that these could exert allosteric effects on the paratope. They identified a large hydrophobic core of residues in the IgA1 $\mathrm{V}_{\mathrm{H}}-\mathrm{C}_{\mathrm{H} 1}$ interface, as well as a disulfide bridge connecting heavy and light chains which was absent in the $\operatorname{IgG}_{1}$ model. Furthermore, they identified a difference of about $5^{\circ}$ in the angle between the $\mathrm{V}_{\mathrm{H}}-\mathrm{C}_{\mathrm{H} 1}$ domains of the two Fabs which modifies the $\mathrm{V}_{\mathrm{H}}-\mathrm{V}_{\mathrm{L}}$ arrangement. This subtle change may result in allosteric effects that lead to critical rearrangements of the paratope. These constraints ultimately led to an increased rigidity of the IgA1 molecule and different conformational entropy that is hypothesized to correlate to $\mathrm{Ag}$ binding affinity modulation (Correa et al., 2013). 
A comparison of human and murine mAb IgG isotypes using the full ensemble optimization method and SAXS data of these isotypes by two separate groups revealed important conformational differences (Eryilmaz et al., 2013; Tian et al., 2015). Eryilmaz et al. proposed that differences in global structures of isotypes are due to cross-domain relationships between various $\mathrm{V}$ and $\mathrm{C}$ region combinations. They hypothesized that these relationships can dramatically change the overall shape of an Ig (Eryilmaz et al., 2013). This was supported by studies by Tian et al. which showed that differences seen in Ag binding may be related to intermolecular Fab-Fab and Fab-Fc interactions. This was based on the significant differences in hinge angles and the type of overall conformation that was adopted by the IgG molecules they used (Tian et al., 2015).

Recent studies comparing 141 crystal structures of Abs with and without $\mathrm{Ag}$ provided additional insight into $\mathrm{C}$ region involvement in $\mathrm{Ag}$ binding. These studies show that $\mathrm{Ag}$ binding is associated with changes in (1) $\mathrm{H}$ and $\mathrm{L}$ chain relative orientations in both $\mathrm{C}$ and $\mathrm{V}$ domains, (2) elbow angles between $\mathrm{V}$ and $\mathrm{C}$ regions, especially when binding large Ags, and (3) $\mathrm{C}_{\mathrm{H} 1}$ loops implicated in interactions between $\mathrm{H}$ and $\mathrm{L}$ chains which show the most consistent and substantial changes upon Ag binding. Although the group only compared pairs of structures solved with the same space group, no two pairs had similar unit cell sizes. However, these results were consistent among many pairs of Fabs and their Fab-Ag structures, and provide some insight into how C-region mediated allosteric effects could potentially transmit to the $\mathrm{V}$ region (Sela-Culang et al., 2013).

\section{ANTIGEN-INDUCED CHANGES IN FC REGION}

It is also worth mentioning that there are a few studies that have hypothesized allosteric changes in Fc regions upon Ag binding, thus promoting $\mathrm{Ab}$ effector functions. This strengthens the argument for Ig inter-molecular signaling through specific structural interactions. For example, in 1970's Brown and Koshland identified changes in J-chain exposure in $\mathrm{C}_{\mathrm{H} 4} \mathrm{Fc}$ regions of IgM molecules that were directly induced by monovalent Ag binding to the Fab region. Their studies excluded cross-linked Ags (Brown and Koshland, 1975, 1977). In addition, studies by Schlessinger et al. using Trp fluorescence and monovalent Ags with anti-RNase Abs demonstrated significantly different $\mathrm{C}$-region changes in both $\mathrm{Fab}$ and whole $\mathrm{Ab}$ upon $\mathrm{Ag}$ binding. This suggests an interaction between Ag binding sites and distant $\mathrm{Fc}$ regions. When they reduced the inter-chain disulfide bonds of the Fabs and whole Abs, they no longer saw

\section{REFERENCES}

Adachi, M., Kurihara, Y., Nojima, H., Takeda-Shitaka, M., Kamiya, K., and Umeyama, H. (2003). Interaction between the antigen and antibody is controlled by the constant domains: normal mode dynamics of the HELHyHEL-10 complex. Protein Sci. 12, 2125-2131. doi: 10.1110/ps.03100803

Adame-Gallegos, J. R., Shi, J., McIntosh, R. S., and Pleass, R. J. (2012). The generation and evaluation of two panels of epitope-matched mouse IgG1, these changes in whole $\mathrm{Ab}$ molecules. This work indicates that disulfide bonding especially at the $\mathrm{Ab}$ hinge region is required for the transmission of allosteric signaling from the Fab region to the Fc in these Ab molecules (Schlessinger et al., 1975). Another study, which assessed IgG Fc binding to staphylococcal protein $A$ and streptococcal protein $\mathrm{G}$ proteins (which bind to $\mathrm{Ig} \mathrm{C}$ domains), identified inhibition of binding in the presence of $\mathrm{Ag}$, presumably through changes to the Fc region. These observations were also made in the presence of a reducing environment (Oda et al., 2003). These studies raise the question of Ig allosteric effects that occur after Ag binding and travel down the molecule to induce changes in the Ig Fc region.

\section{CONCLUDING REMARKS}

Since the initial findings that Ig $\mathrm{C}$ regions can change the $\mathrm{Ag}$ binding parameters of their $\mathrm{V}$ regions, more recent studies have begun to attempt to elucidate the allosteric mechanisms through which these effects may be occurring. Many studies have now shown that inter-molecular interactions between heavy and light chains, $\mathrm{V}$ and $\mathrm{C}$ regions, hinges and elbow relationships, all can play a vital role in the overall molecular structure of the Ig paratope in relationship to its affinity and specificity for Ag. In particular, the $\mathrm{C}_{\mathrm{H} 1}$ region seems to play a large role in determining $\mathrm{Ag}$ binding parameters, most likely through its intermolecular interactions with both its neighboring $\mathrm{C}_{\mathrm{L}}$ domain as well as by transmitting structural information to the Ig hinge region and back to the $\mathrm{V}_{\mathrm{H}}$ domain.

\section{AUTHOR CONTRIBUTIONS}

AJ wrote the manuscript, Table 1, and edited the document to prepare for submission. AB put together Figures 1, 2, and Table 2 and also edited the paper. NG contributed with writing and editing the review. AC is the corresponding author, he wrote and edited the review.

\section{FUNDING}

AC was supported by NIH awards HL059842, AI033774, AI052733, AI033142. AJ wishes to acknowledge support from the Institutional AIDS training grant T32-AI007501 and the MSTP training grant, T32-GM007288. AB wishes to acknowledge support from the MSTP training grant: T32-GM007288. Authors $\mathrm{AC}, \mathrm{AJ}$ and $\mathrm{AB}$ would also like to acknowledge funding from Albert Einstein College of Medicine, Yeshiva University.

IgG2a, IgG2b and IgG3 antibodies specific for Plasmodium falciparum and Plasmodium yoelii merozoite surface protein 1-19 (MSP1(19)). Exp. Parasitol. 130, 384-393. doi: 10.1016/j.exppara.2012.02.003

Benacerraf, B., Sebesteyn, M., and Cooper, N. S. (1959). The clearance of antigen antibody complexes from the blood by the reticuloendothelial system. $J$. Immunol. 82, 131-137.

Brown, J. C., and Koshland, M. E. (1975). Activation of antibody Fc function by antigen-induced conformational changes. Proc. 
Natl. Acad. Sci. U.S.A. 72, 5111-5115. doi: 10.1073/pnas.72. 12.5111

Brown, J. C., and Koshland, M. E. (1977). Evidence for a long-range conformational change induced by antigen binding to IgM antibody. Proc. Natl. Acad. Sci. U.S.A. 74, 5682-5686. doi: 10.1073/pnas.74.12.5682

Casadevall, A., and Janda, A. (2012). Immunoglobulin isotype influences affinity and specificity. Proc. Natl. Acad. Sci. U.S.A. 109, 12272-12273. doi: 10.1073/pnas. 1209750109

Cavacini, L. A., Emes, C. L., Wisnewski, A. V., Power, J., Lewis, G., Montefiori, D., et al. (1998). Functional and molecular characterization of human monoclonal antibody reactive with the immunodominant region of HIV type 1 glycoprotein 41. AIDS Res. Hum. Retroviruses 14, 1271-1280. doi: 10.1089/aid.1998. 14.1271

Chothia, C., Lesk, A. M., Tramontano, A., Levitt, M., Smith-Gill, S. J., Air, G., et al. (1989). Conformations of immunoglobulin hypervariable regions. Nature 342, 877-883. doi: $10.1038 / 342877 \mathrm{a} 0$

Cooper, L. J., Robertson, D., Granzow, R., and Greenspan, N. S. (1994). Variable domain-identical antibodies exhibit IgG subclass-related differences in affinity and kinetic constants as determined by surface plasmon resonance. Mol. Immunol. 31, 577-584. doi: 10.1016/0161-5890(94)90165-1

Cooper, L. J., Schimenti, J. C., Glass, D. D., and Greenspan, N. S. (1991). H chain $\mathrm{C}$ domains influence the strength of binding of IgG for streptococcal group A carbohydrate. J. Immunol. 146, 2659-2663.

Cooper, L. J., Shikhman, A. R., Glass, D. D., Kangisser, D., Cunningham, M. W., and Greenspan, N. S. (1993). Role of heavy chain constant domains in antibodyantigen interaction. Apparent specificity differences among streptococcal IgG antibodies expressing identical variable domains. J. Immunol. 150, 2231-2242.

Correa, A., Trajtenberg, F., Obal, G., Pritsch, O., Dighiero, G., Oppezzo, P., et al. (2013). Structure of a human IgA1 Fab fragment at $1.55 \mathrm{~A}$ resolution: potential effect of the constant domains on antigen-affinity modulation. Acta Crystallogr. D Biol. Crystallogr. 69, 388-397. doi: 10.1107/S0907444912048664

Crespillo, S., Casares, S., Mateo, P. L., and Conejero-Lara, F. (2014). Thermodynamic analysis of the binding of 2F5 (Fab and immunoglobulin G forms) to its gp41 epitope reveals a strong influence of the immunoglobulin Fc region on affinity. J. Biol. Chem. 289, 594-599. doi: 10.1074/jbc.C113.524439

Dam, T. K., Torres, M., Brewer, C. F., and Casadevall, A. (2008). Isothermal titration calorimetry reveals differential binding thermodynamics of variable region-identical antibodies differing in constant region for a univalent ligand. J. Biol. Chem. 283, 31366-31370. doi: 10.1074/jbc.M806473200

Davies, D. R., Padlan, E. A., and Segal, D. M. (1975). Three-dimensional structure of immunoglobulins. Annu. Rev. Biochem. 44, 639-667. doi: 10.1146/annurev.bi.44.070175.003231

Dodev, T. S., Bowen, H., Shamji, M. H., Bax, H. J., Beavil, A. J., McDonnell, J. M., et al. (2015). Inhibition of allergen-dependent IgE activity by antibodies of the same specificity but different class. Allergy 70, 720-724. doi: 10.1111/all.12607

Dreyer, W. J., and Bennett, J. C. (1965). The molecular basis of antibody formation: a paradox. Proc. Natl. Acad. Sci. U.S.A. 54, 864-869. doi: 10.1073/pnas.54.3.864

Eryilmaz, E., Janda, A., Kim, J., Cordero, R. J., Cowburn, D., and Casadevall, A. (2013). Global structures of IgG isotypes expressing identical variable regions. Mol. Immunol. 56, 588-598. doi: 10.1016/j.molimm.2013.06.006

Feinstein, A. and Rowe, A. J. (1965). Molecular mechanisms of formation of antigen-antibody complex. Nature 205, 147-149. doi: 10.1038/205147a0

French, H. D., Porter, R. W., Cavanaugh, E. B., and Longmire, R. L. (1957). Experimental gastroduodenal lesions induced by stimulation of the brain. Psychosom. Med. 19, 209-220. doi: 10.1097/00006842-195705000-00006

Fulpius, T., Spertini, F., Reininger, L., and Izui, S. (1993). Immunoglobulin heavy chain constant region determines the pathogenicity and the antigen-binding activity of rheumatoid factor. Proc. Natl. Acad. Sci. U.S.A. 90, 2345-2349. doi: 10.1073/pnas.90.6.2345

Greenspan, N. S., and Cooper, L. J. (1993). Cooperative binding by mouse IgG3 antibodies: implications for functional affinity, effector function, and isotype restriction. Springer Semin. Immunopathol. 15, 275-291. doi: 10.1007/BF00201107

Greenspan, N. S., Monafo, W. J., and Davie, J. M. (1987). Interaction of IgG3 anti-streptococcal group A carbohydrate (GAC) antibody with streptococcal group A vaccine: enhancing and inhibiting effects of anti-GAC, anti-isotypic, and anti-idiotypic antibodies. J. Immunol. 138, 285-292.
Harris, L. J., Larson, S. B., Hasel, K. W., and McPherson, A. (1997). Refined structure of an intact IgG2a monoclonal antibody. Biochemistry 36, 1581-1597. doi: $10.1021 /$ bi962514+

Harris, L. J., Skaletsky, E., and McPherson, A. (1998). Crystallographic structure of an intact IgG1 monoclonal antibody. J. Mol. Biol. 275, 861-872. doi: 10.1006/jmbi.1997.1508

Hovenden, M., Hubbard, M. A., Aucoin, D. P., Thorkildson, P., Reed, D. E., Welch, W. H., et al. (2013). IgG subclass and heavy chain domains contribute to binding and protection by $\mathrm{mAbs}$ to the poly gamma-D-glutamic acid capsular antigen of Bacillus anthracis. PLoS Pathog. 9:e1003306. doi: 10.1371/journal.ppat.1003306

Huber, R., Deisenhofer, J., Colman, P. M., Matsushima, M., and Palm, W. (1976). Crystallographic structure studies of an IgG molecule and an Fc fragment. Nature 264, 415-420. doi: 10.1038/264415a0

James, L. C., and Tawfik, D. S. (2003). Conformational diversity and protein evolution-a 60-year-old hypothesis revisited. Trends Biochem. Sci. 28, 361-368. doi: 10.1016/S0968-0004(03)00135-X

Janda, A., and Casadevall, A. (2010). Circular Dichroism reveals evidence of coupling between immunoglobulin constant and variable region secondary structure. Mol. Immunol. 45, 1421-1425. doi: 10.1016/j.molimm.2010.02.018

Janda, A., Eryilmaz, E., Nakouzi, A., Cowburn, D., and Casadevall, A. (2012). Variable region identical immunoglobulins differing in isotype express different paratopes. J. Biol. Chem. 287, 35409-35417. doi: 10.1074/jbc.M112.404483

Janda, A., Eryilmaz, E., Nakouzi, A., Pohl, M. A., Bowen, A., and Casadevall, A. (2015). Variable region identical IgA and IgE to Cryptococcus neoformans capsular polysaccharide manifest specificity differences. J. Biol. Chem. 290, 12090-12100. doi: 10.1074/jbc.M114.618975

Kabat, E. A., Padlan, E. A., and Davies, D. R. (1975). Evolutionary and structural influences on light chain constant (CL) region of human and mouse immunoglobulins. Proc. Natl. Acad. Sci. U.S.A. 72, 2785-2788.

Kabat, E. A., Wu, T. T., and Bilofsky, H. (1977). Unusual distributions of amino acids in complementarity-determining (hypervariable) segments of heavy and light chains of immunoglobulins and their possible roles in specificity of antibody-combining sites. J. Biol. Chem. 252, 6609-6616.

Kato, K., Matsunaga, C., Odaka, A., Yamato, S., Takaha, W., Shimada, I., et al. (1991). Carbon-13 NMR study of switch variant anti-dansyl antibodies: antigen binding and domain-domain interactions. Biochemistry 30, 6604-6610. doi: 10.1021/bi00240a 033

Kelly-Quintos, C., Cavacini, L. A., Posner, M. R., Goldmann, D., and Pier, G. B. (2006). Characterization of the opsonic and protective activity against Staphylococcus aureus of fully human monoclonal antibodies specific for the bacterial surface polysaccharide poly- $\mathrm{N}$-acetylglucosamine. Infect. Immun. 74, 2742-2750. doi: 10.1128/IAI.74.5.2742-2750.2006

Kozel, T. R., Thorkildson, P., Brandt, S., Welch, W. H., Lovchik, J. A., Aucoin, D. P., et al. (2007). Protective and immunochemical activities of monoclonal antibodies reactive with the Bacillus anthracis polypeptide capsule. Infect. Immun. 75, 152-163. doi: 10.1128/IAI.01133-06

Kunert, R., Ruker, F., and Katinger, H. (1998). Molecular characterization of five neutralizing anti-HIV type 1 antibodies: identification of nonconventional D segments in the human monoclonal antibodies $2 \mathrm{G} 12$ and $2 \mathrm{~F} 5$. AIDS Res. Hum. Retroviruses 14, 1115-1128. doi: 10.1089/aid.1998.14.1115

Lange, H., Solterbeck, M., Berek, C., and Lemke, H. (1996). Correlation between immune maturation and idiotypic network recognition. Eur. J. Immunol. 26, 2234-2242. doi: 10.1002/eji.1830260940

Lavoie, T. B., Drohan, W. N., and Smith-Gill S. J. (1992). Experimental analysis by site-directed mutagenesis of somatic mutation effects on affinity and fine specificity in antibodies specific for lysozyme. J. Immunol. 148, 503-513.

Liu, F., Bergami, P. L., Duval, M., Kuhrt, D., Posner, M., and Cavacini, L. (2003). Expression and functional activity of isotype and subclass switched human monoclonal antibody reactive with the base of the V3 loop of HIV-1 gp120. AIDS Res. Hum. Retroviruses 19, 597-607. doi: 10.1089/088922203322230969

Marasco, W. A., Bagley, J., Zani, C., Posner, M., Cavacini, L., Haseltine, W. A., et al. (1992). Characterization of the cDNA of a broadly reactive neutralizing human anti-gp120 monoclonal antibody. J. Clin. Invest. 90, 1467-1478. doi: 10.1172/JCI116014

McLean, G. R., Torres, M., Elguezabal, N., Nakouzi, A., and Casadevall, A. (2002). Isotype can affect the fine specificity of an antibody for a polysaccharide antigen. J. Immunol. 169, 1379-1386. doi: 10.4049/jimmunol.169.3.1379 
Morelock, M. M., Rothlein, R., Bright, S. M., Robinson, M. K., Graham, E. T., Sabo, J. P., et al. (1994). Isotype choice for chimeric antibodies affects binding properties. J. Biol. Chem. 269, 13048-13055.

Mukherjee, J. (1992). Characterization of Hybridomas and Monoclonal Antibodies Elicited by Cryptococcus neoformans. Ph.D., Albert Einstein College of Medicine.

Nosanchuk, J. D. (2013). The interdependence of antibody C and V regions on specificity and affinity: significant implications for the engineering of therapeutic antibodies. Virulence 4, 439-440. doi: 10.4161/viru.26153

Oda, M., Kozono, H., Morii, H., and Azuma, T. (2003). Evidence of allosteric conformational changes in the antibody constant region upon antigen binding. Int. Immunol. 15, 417-426. doi: 10.1093/intimm/dxg036

Oi, V. T., Vuong, T. M., Hardy, R., Reidler, J., Dang, J., Herzenberg, L. A., et al. (1984). Correlation between segmental flexibility and effector function of antibodies. Nature 307, 136-140. doi: 10.1038/307136a0

Pollack, M., Koles, N. L., Preston, M. J., Brown, B. J., and Pier, G. B. (1995). Functional properties of isotype-switched immunoglobulin M (IgM) and IgG monoclonal antibodies to Pseudomonas aeruginosa lipopolysaccharide. Infect. Immun. 63, 4481-4488.

Porter, R. R. (1957). The isolation and properties of a fragment of bovine-serum albumin which retains the ability to combine with rabbit antiserum. Biochem. J. 66, 677-686. doi: 10.1042/bj0660677

Porter, R. R., and Press, E. M. (1957). The fractionation of bovine delta-globulin by partition chromatography. Biochem. J. 66, 600-603. doi: 10.1042/bj0660600

Pritsch, O., Hudry-Clergeon, G., Buckle, M., Petillot, Y., Bouvet, J. P., Gagnon, J., et al. (1996). Can immunoglobulin $\mathrm{C}(\mathrm{H}) 1$ constant region domain modulate antigen binding affinity of antibodies? J. Clin. Invest. 98, 2235-2243. doi: 10.1172/JCI119033

Pritsch, O., Magnac, C., Dumas, G., Bouvet, J. P., Alzari, P., and Dighiero, G. (2000). Can isotype switch modulate antigen-binding affinity and influence clonal selection? Eur. J. Immunol. 30, 3387-3395. doi: 10.1002/15214141(2000012)30:12<3387::AID-IMMU3387>3.0.CO;2-K

Reitan, S. K., and Hannestad, K. (1995). A syngeneic idiotype is immunogenic when borne by IgM but tolerogenic when joined to IgG. Eur. J. Immunol. 25, 1601-1608. doi: 10.1002/eji.1830250620

Reitan, S. K., and Hannestad, K. (2001). The primary IgM antibody repertoire: a source of potent idiotype immunogens. Eur. J. Immunol. 31, 2143-2153. doi: 10.1002/1521-4141(200107)31:7<2143::AID-IMMU2143>3.0.CO;2-1

Saphire, E. O., Stanfield, R. L., Crispin, M. D., Parren, P. W., Rudd, P. M., Dwek, R. A., et al. (2002). Contrasting IgG structures reveal extreme asymmetry and flexibility. J. Mol. Biol. 319, 9-18. doi: 10.1016/S0022-2836(02)00244-9

Schlessinger, J., Steinberg, I. Z., Givol, D., Hochman, J., and Pecht, I. (1975). Antigen-induced conformational changes in antibodies and their Fab fragments studied by circular polarization of fluorescence. Proc. Natl. Acad. Sci. U.S.A. 72, 2775-2779. doi: 10.1073/pnas.72.7.2775

Schreiber, J. R., Cooper, L. J., Diehn, S., Dahlhauser, P. A., Tosi, M. F., Glass, D. D., et al. (1993). Variable region-identical monoclonal antibodies of different IgG subclass directed to Pseudomonas aeruginosa lipopolysaccharide O-specific side chain function differently. J. Infect. Dis. 167, 221-226. doi: 10.1093/infdis/167.1.221

Segal, D. M., Padlan, E. A., Cohen, G. H., Rudikoff, S., Potter, M., and Davies, D. R. (1974). The three-dimensional structure of a phosphorylcholine-binding mouse immunoglobulin Fab and the nature of the antigen binding site. Proc. Natl. Acad. Sci. U.S.A. 71, 4298-4302. doi: 10.1073/pnas.71.11.4298

Sela-Culang, I., Kunik, V., and Ofran, Y. (2013). The structural basis of antibodyantigen recognition. Front. Immunol. 4. doi: 10.3389/fimmu.2013.00302

Shinomiya, T., and Koyama, J. (1976). In vitro uptake and digestion of immune complexes containing guinea-pig IgG1 and IgG2 antibodies by macrophages. Immunology 30, 267.

Stryer, L. (1968). Implications of X-ray crystallographic studies of protein structure. Annu. Rev. Biochem. 37, 25-50. doi: 10.1146/annurev.bi.37.070168.000325

Stryer, L., and Griffith, O. H. (1965). A spin-labeled hapten. Proc. Natl. Acad. Sci. U.S.A. 54, 1785-1791. doi: 10.1073/pnas.54.6.1785

Tian, X., Vestergaard, B., Thorolfsson, M., Yang, Z., Rasmussen, H. B., and Langkilde, A. E. (2015). In-depth analysis of subclass-specific conformational preferences of IgG antibodies. IUCr J. 2, 9-18. doi: $10.1107 /$ S205225251402209X
Tomaras, G. D., Ferrari, G., Shen, X., Alam, S. M., Liao, H. X., Pollara, J., et al. (2013). Vaccine-induced plasma IgA specific for the C1 region of the HIV1 envelope blocks binding and effector function of IgG. Proc. Natl. Acad. Sci. U.S.A. 110, 9019-9024. doi: 10.1073/pnas.1301456110

Tonegawa, S. (1983). Somatic generation of antibody diversity. Nature 302, 575-581. doi: 10.1038/302575a0

Torosantucci, A., Chiani, P., Bromuro, C., de Bernardis, F., Palma, A. S., Liu, Y., et al. (2009). Protection by anti-beta-glucan antibodies is associated with restricted beta-1,3 glucan binding specificity and inhibition of fungal growth and adherence. PLoS ONE 4:e5392. doi: 10.1371/journal.pone.0005392

Torres, M., and Casadevall, A. (2008). The immunoglobulin constant region contributes to affinity and specificity. Trends Immunol. 29, 91-97. doi: 10.1016/j.it.2007.11.004

Torres, M., Fernández-Fuentes, N., Fiser, A., and Casadevall, A. (2007a). Exchanging murine and human immunoglobulin constant chains affects the kinetics and thermodynamics of antigen binding and chimeric antibody autoreactivity. PLoS ONE 2:e1310. doi: 10.1371/journal.pone.0001310

Torres, M., Fernandez-Fuentes, N., Fiser, A., and Casadevall, A. (2007b). The immunoglobulin heavy chain constant region affects kinetic and thermodynamic parameters of antibody variable region interactions with antigen. J. Biol. Chem. 282, 13917-13927. doi: 10.1074/jbc.M700661200

Torres, M., May, R., Scharff, M. D., and Casadevall, A. (2005). Variableregion-identical antibodies differing in isotype demonstrate differences in fine specificity and idiotype. J. Immunol. 174, 2132-2142. doi: 10.4049/jimmunol.174.4.2132

Tudor, D., Yu, H., Maupetit, J., Drillet, A. S., Bouceba, T., Schwartz-Cornil, I., et al. (2012). Isotype modulates epitope specificity, affinity, and antiviral activities of anti-HIV-1 human broadly neutralizing 2F5 antibody. Proc. Natl. Acad. Sci. U.S.A. 109, 12680-12685. doi: 10.1073/pnas.1200024109

Walker, L. M., Huber, M., Doores, K. J., Falkowska, E., Pejchal, R., Julien, J. P., et al. (2011). Broad neutralization coverage of HIV by multiple highly potent antibodies. Nature 477, 466-470. doi: 10.1038/ nature10373

Werner, T. C., Bunting, J. R., and Cathou, R. E. (1972). The shape of immunoglobulin G molecules in solution. Proc. Natl. Acad. Sci. U.S.A. 69, 795-799. doi: 10.1073/pnas.69.4.795

Xia, Y., Janda, A., Eryilmaz, E., Casadevall, A., and Putterman, C. (2013). The constant region affects antigen binding of antibodies to DNA by altering secondary structure. Mol. Immunol. 56, 28-37. doi: 10.1016/j.molimm.2013.04.004

Xia, Y., Pawar, R. D., Nakouzi, A. S., Herlitz, L., Broder, A., Liu, K., et al. (2012). The constant region contributes to the antigenic specificity and renal pathogenicity of murine anti-DNA antibodies. J. Autoimmun. 39, 398-411. doi: 10.1016/j.jaut.2012.06.005

Yguerabide, J., Epstein, H. F., and Stryer, L. (1970). Segmental flexibility in an antibody molecule. J. Mol. Biol. 51, 573-590. doi: 10.1016/0022-2836(70) 90009-4

Yuan, R., Casadevall, A., Spira, G., and Scharff, M. D. (1995). Isotype switching from IgG3 to IgG1 converts a nonprotective murine antibody to Cryptococcus neoformans into a protective antibody. J. Immunol. 154, 1810-1816.

Yuan, R. R., Spira, G., Oh, J., Paizi, M., Casadevall, A., and Scharff, M. D. (1998). Isotype switching increases efficacy of antibody protection against Cryptococcus neoformans infection in mice. Infect. Immun. 66, 1057-1062.

Zaghouani, H., Bonilla, F. A., Meek, K., and Bona, C. (1989). Molecular basis for expression of the A48 regulatory idiotope on antibodies encoded by immunoglobulin variable-region genes from various families. Proc. Natl. Acad. Sci. U.S.A. 86, 2341-2345. doi: 10.1073/pnas.86.7.2341

Conflict of Interest Statement: The authors declare that the research was conducted in the absence of any commercial or financial relationships that could be construed as a potential conflict of interest.

Copyright (c) 2016 Janda, Bowen, Greenspan and Casadevall. This is an open-access article distributed under the terms of the Creative Commons Attribution License (CC $B Y)$. The use, distribution or reproduction in other forums is permitted, provided the original author(s) or licensor are credited and that the original publication in this journal is cited, in accordance with accepted academic practice. No use, distribution or reproduction is permitted which does not comply with these terms. 